\title{
Determination of Thermal Bioclimatic Conditions for Touristsin west and North West of Iran using PET
}

\author{
Ali. Hanafi ${ }^{1}$, Hasan. Atashgahi ${ }^{2}$ \\ ${ }^{1}$ AssistantProfessor of Climatology, Faculty of Basic sciences, University of Imam Ali, Tehran, Iran \\ ${ }^{2} \mathrm{MSc}$ of Geographic Information System, Faculty of Basic sciences, University of Imam Ali, Tehran, Iran
}

\begin{abstract}
Tourism has become an important sector that has an impact on development of country economy. The main benefits of tourism are income creation and generation of jobs. For many regions and countries it is the most important source of welfare.The purpose of this study is to determine the most suitable months for human thermal comfort and tourism activities in west and North Westof Iran by using Physiologically Equivalent Temperature(PET).The data, which covering the period 1985-2010, from a dense network of 32 meteorological stations in west and north west $f$ of Iran was used to compute the PET. Mean air temperature, relative humidity, vapor pressure, wind speed, and cloud cover data were obtained from theIran Meteorological Organization (IRIMO).Ray Man model was used to calculate the PET. Based on the calculations of PET in the region, it is shown that the monthsMarch and Decemberin the west parts of Kermanshah, the monthsApril, May and October in Kermanshah and Kurdistan and the June and September in the northern parts of the region such as Azerbaijan, and Hamadan are laying in the comfortable class that representing the most suitable months for tourism and tourist activities.
\end{abstract}

Keywords- Tourism, physiologically equivalent temperature (PET), climatic comfort, Ray Man, west and North West of Iran.

\section{INTRODUCTION}

Nowadays tourism industry is developing into one of the most important and most lucrative industries worldwide. In 2012, international tourist arrivals exceeded one billion for the first time in history, contributing $9 \%$ to global GDP, 1.3 US\$trillion in exports (United Nations World Tourism Organization 2013, Rutty and Scott 2014).Tourism is heavily depended on weather and climate in such a way that fair weather and climate knowledge of destination play a key role in tourism industry and they can be attracting or off putting factors for tourists (Fallahi et al, 2012).Usually, geographical location, topography, landscape, vegetation and fauna are factors that influence decisions regarding areas to be visited. Weather and climate are two additional factors (Matzarakis, 2006; Farajzadeh and Matzarakis, 2009). Climate and tourism are closely related and the relationship between these two is indicated whereby "Climate Comfort Index"(Ataei et al, 2013). The climatic indices, which are primary used for tourism climate assessments and thermal comfort studies, present a certain number of important points. From the point of view of human-biometeorology they do not include the effects of short and long wave radiation fluxes which are generally not available in climate records. The required, for the human energy balance, short and long wave radiation fluxes are calculated using synoptic and climatological and astronomical data (VDI 1998; Matzarakis et al 2000; Matzarakis 2007).

Commonly used indices that measure the effect of the thermal environment on humans are PMV (Predicted Mean Vote) (Fanger 1972), PET (Physiological Equivalent Temperature) (Höppe, 1999, Matzarakis et al, 1999), and SET* (standard effectivetemperature) (Gagge et al. 1986). The advantage of these thermal indices is that they require the same meteorological input parameters i.e. air temperature, air humidity, wind speed, short and long wave radiation fluxes (Matzarakis 2007). The physiologically equivalent temperature (PET) is a thermal index derived from the human energy balance. It is well suited to the evaluation of the thermal component of different climates. PET is preferable to other thermal indexes such as the predicted mean vote because of its units $\left({ }^{\circ} \mathrm{C}\right)$, which make results more comprehensible to urban or regional planners. PET results can be presented graphically or as bioclimatic maps(Matzarakis et al., 1999).In this regard Rayman which is an improved model calculates the average radiant temperature and thermal indexes in simple and complex environments based on the data from weather stations and climatic elements such as temperature, humidity and wind 
speed (Matzarakis 2009). This model can be used to evaluate urban bioclimate and thermal indexes including (PET), (SET) and (PMV).

Iran, among the world's eighth leading countries considering its cultural and historical sites, and based on the diversity of landscape and continental ecotourism attractions, ranked in the top five countries of the world (Esmaili and Fallah Ghalhari, 2014).However, little research has been done to establish environmental and continental information for tourists that can notethefollowingresearch:

Matzarakis and Farajzadeh (2009), in a paper entitled "Quantification of climate for tourism in the northwest of Iran " concluded that all the stations in northwest Iran have a month with (TCI) over 80 which can be considered an ideal index comfort. Esmaili and Fallah Ghalhari (2014) havestudiedBioclimatic Conditions of Mashhad for Tourists activities and concluded themonths of April, May and October have thebestbioclimate condition in Mashhad.Ataei and Hashemi Nasab (2012), in a research Evaluated Human Bioclimate of Semnan Province by using (PET) and (PMV) and showed thatinthe months ofOctober and November comfortclimateprevailinginthe city.

Ranjbar et al (2009), in a paper studied the relation between climatic conditions and annual tourism trend in the city of Marvdasht. Ataei et al (2013) determineda suitable calendar for tourism in Ahwaz usingPET and Concluded that Ahwaz has comfortable and suitable conditions during the cold seasons of the year and is the best destination for tourists in the winter.

Because oftheavailability of largetourist attractionsinWestand Northwest of Iran, the purpose of this study was to examine and analyze the thermal bioclimate (physiologically equivalenttemperature) and determine the most suitable months for tourist activities in the west and north west of Iran.

\section{STUDY AREA}

The study area is located between $29^{\circ} 58^{\prime}$ to $39^{\circ} 49^{\prime}$ latitude and $44^{\circ} 03^{\prime}$ to $50^{\circ} 39^{\prime}$ longitude and includes the west and north west of Iran. This region has a diverse climate. In the northwest, winters are cold with heavy snowfall and subzero temperatures during December and January.

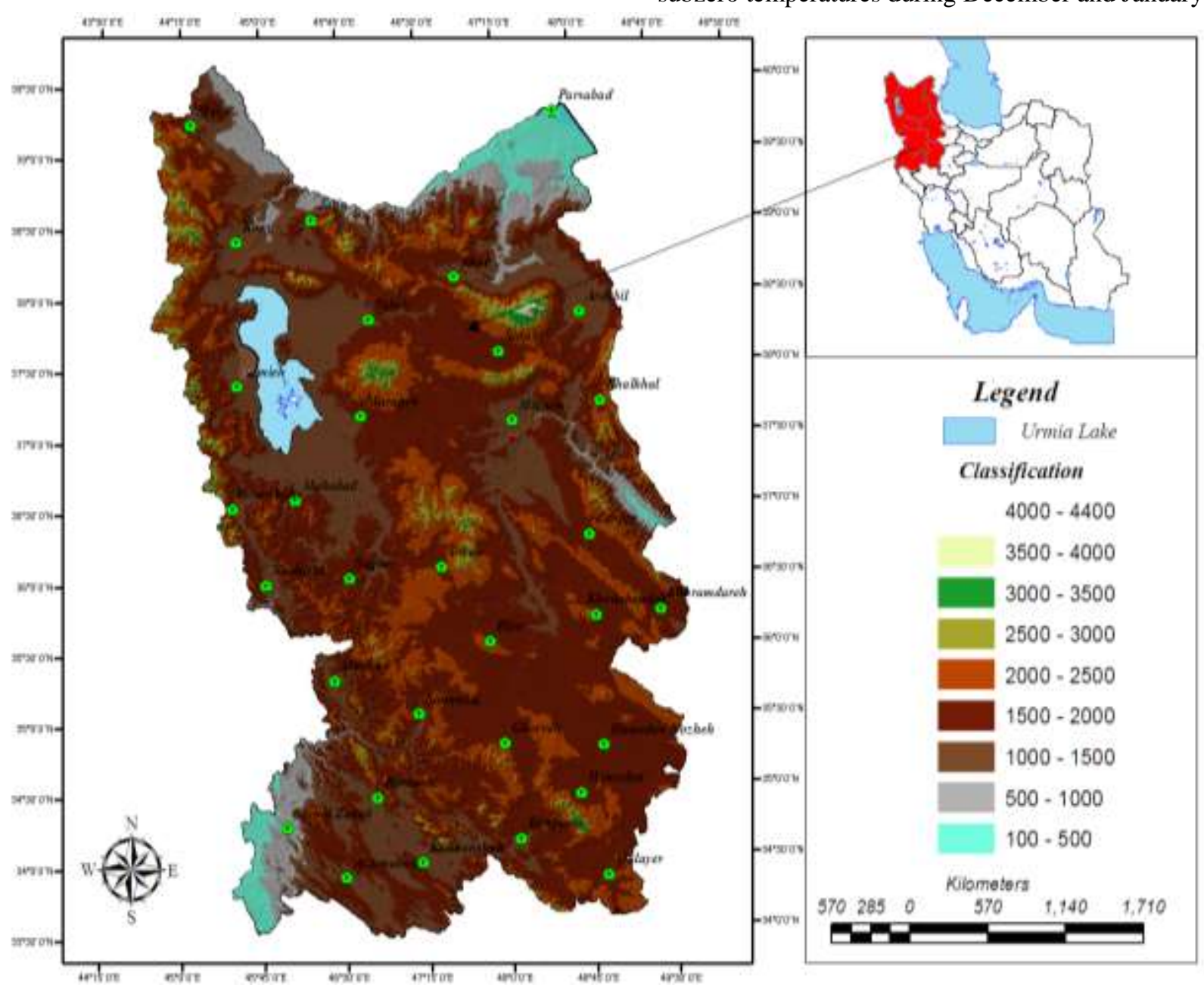

Fig.1: Topographic map, weather stations and geographical location of the study area 
Spring and fall are rather mild, while summers are dry and hot. In the south, winters are mild and the summers are hot. In general, the west of Iran has plentiful cultural, historical and environmental attractions (ecotourism) consideringas one of the most potential spots for tourist capacity.More than 100 tourism landmarks, plentiful cultural, historical and natural attractions (ecotourism and geotourism) and variety of climates can be found in the region and are mostly visited by the domestic and foreign tourists.In this region, the following provinces are located: WestAzerbaijan, East Azerbaijan, Zanjan, Kurdistan, Ardabil, Kermanshah and Hamadan (Figure 1). Uremia lake and Sahulan cave palace in West Azerbaijan, Arasbaran forests and Kandovan village in East Azerbaijan, Qezel Ozan River and Soltanieh Dome in Zanjan, Sabalan Mountainsand Sar Ein Mineral Springs in Ardabil, Alisadr cave in Hamadan, zarivar lake in Kurdistan, Bistun vault in Kermanshah are also interesting locations for visitors.

\section{DATA AND METHODS}

In the present study to assess Physiological Equivalent Temperature, the climatic data of 32 synoptic stations over a 25- year time period (1985-2010) were obtained in a quality controlled format from the I. R.of Iran MeteorologicalOrganization (IRIMO). The meteorological elements dry temperature in Celsius, relative airhumidity in percent, wind speed in meter per second, vapor pressure in $\mathrm{hPa}$, the cloud amount in Octa are necessary for calculating PET.The mean radiant temperature can be calculated by combining the theoretical maximum global radiation and the mean cloud cover within the radiation and bioclimate model Ray Man (Matzarakis et al, 2000). The obtained data were fed into Excel program. Next, considering compatibility with (PET) method they were fed into Ray Man and finally the outputs were analyzed. The Humanmeteorological conditions are analyzed by means of 25 -day mean values of thermal sensation measured at $7 \mathrm{am}$, $2 \mathrm{pm}$ and $9 \mathrm{pm}$ during the year.
The thermal sensation is defined by means of physiologically equivalent temperature PET as the physiologically significant assessment of the thermal environment derived from the human energy balance (Höppe, 1999, Matzarakis et al., 1999, Matzarakis 2007). Since the 1960s, heat balance models of the human body have become more andmore accepted in assessing thermal comfort. More universally applicable models take into account all basic thermoregulatory processes, like the constriction or dilation of peripheral blood vessels and the physiological sweat rate (Höppe 1993, 1999). The Munich energy balance model for individuals" (MEMI) (Höppe 1993) is such a thermo physiological heat balance model. It is the basis for calculating the physiologically equivalent temperature (PET).PET is defined to be equivalent to the air temperature that is required to reproduce in a standardized indoor setting and for a standardized person the core and skintemperatures that are observed under the conditions being assessed (VDI 1998; Höppe 1999, Matzarakis 2007). The standardized person is characterized by a work metabolism of $80 \mathrm{~W}$ of light activity, in addition to basic metabolism; andby 0.9 clo of heat resistance as a result of clothing.

The calculation of PET includes the following steps:

- Calculation of the thermal conditions of the body with MEMI for a given combination of meteorological parameters.

- Insertion of the calculated values for mean skin temperature and core temperature into the model MEMI and solving the energy balance equation system for the air temperature Ta (with $\mathrm{v}=0.1 \mathrm{~m} / \mathrm{s}, \mathrm{VP}=12 \mathrm{hPa}$ and Tmrt $=$ Ta).

Finally the resulting air temperature is equivalent to PET (Matzarakis 2007).PET allows the evaluation of thermal conditions in a physiologically significant manner, too. With respect to this, Matzarakis and Mayer (1996) transferred ranges of PMV for thermal perception and grade of physiological stress on human beings (Fanger 1972) into corresponding PET ranges (Table 1).

Table.1: Ranges of the physiologically equivalent temperature (PET) for different grades of thermal perception by human beings and physiological stress on human beings (Matzarakis and Mayer 1996, Matzarakis 2007)

\begin{tabular}{ccc}
\hline PET & Thermal Perception & Grade of Physiological Stress \\
\hline $4{ }^{\circ} \mathrm{C}$ & very cold & extreme cold stress \\
$8{ }^{\circ} \mathrm{C}$ & Cold & strong cold stress \\
$13{ }^{\circ} \mathrm{C}$ & Cool & moderate cold stress \\
$18^{\circ} \mathrm{C}$ & slightly cool & slight cold stress \\
$23{ }^{\circ} \mathrm{C}$ & Comfortable & no thermal stress \\
$29{ }^{\circ} \mathrm{C}$ & slightly warm & slight heat stress \\
$35^{\circ} \mathrm{C}$ & Warm & moderate heat stress \\
\hline
\end{tabular}




\section{$41{ }^{\circ} \mathrm{C}$}

Hot

strong heat stress

very hot

extreme heat stress

They are valid only for the assumed values of internal heat production and thermal resistance of the clothing. This model can be used to evaluate urban bioclimatic and thermal indexes including (PET), Standard Effective Temperature (SET), Predicted mean Vote (PMV). The model has been developed in Germany according to international guidelines between atmosphere and short-andlong-waive fluxes. Ray man model is a run model for evaluation of bio meteorological weather quality, urban and regional planning at micro and macro level (Matzarakis, 2009).

\section{RESULTS AND DISCUSSION}

Choosing a travel time and destination in terms of climate comfort can positively affect the quality of tourism. Enjoying a fair weather while travelling will increase the tendency to stay longer and coming back to the same spot. In contrast an unfavorable climatic condition enhances a negative experience. According to the PET index (table 1), the numerical value of 18-23 range shows a comfort condition without the warm or cold tensions.In this classification, the numerical values of 23-29 and 13-18 indicate a slightly warm and cool stresses that can wear light or heavy clothes to bring the comfort condition.

In order toobtainan overview ofPET changesin theregion, four stations of Kermanshah, Sanandaj, ,Tabriz and Ardebil were selected from different geographic regions andthe biometeorological conditions are analyzed by means of tenday mean values of thermal sensation during the year. By means of the probability of occurrence of different thermal sensations that enable more detail information about bioclimate.The relative frequencies for PET values divided into10 classes in order to evaluate the thermal stress for the Period from 1985 until 2010.

The relative frequencies for PET in Kermanshah station is shown in Figure 2. In Kermanshah station, thermal comfort occurs from March to June and September to November, with highest Probability $(>30 \%)$ in the months May and October and minimum frequency in July to August (about 0
$\%)$. Cold stress $\left(<4{ }^{\circ} \mathrm{C}\right)$ can be observed from November to March with highest Probability $(>50 \%)$ in the months January and February. Days with strong heat stress, can be observed from June to October with maximum frequencies (Morethan45\%)in the months July andAugust.

Figure 3 shows the relative frequencies for PET in Sanandaj station.In this station, thermal comfort occurs throughout the yearexceptJuly and August, with maximum frequencies $(>30 \%)$ from $10^{\text {st }}$ of May to $10^{\text {th }}$ of June and $10^{\text {th }}$ of September to $20^{\text {st }}$ of Octoberand minimum frequency in December to March (about0\%). Cold stress $\left(<4{ }^{\circ} \mathrm{C}\right)$ can be observed from November to April with highest Probability $(>80 \%)$ in the months January and February.Days with strong heat stress, can be observed from $1^{\text {st }}$ of June to $20^{\text {th }}$ of September with maximum frequencies (Morethan30\%) in the months July and August.

As can be seen in Figure4, in Tabriz station, thermal comfort occurs from April to October, with maximum frequencies ( $>30 \%$ ) from $20^{\text {st }}$ of May to $20^{\text {th }}$ of June and $1^{\text {th }}$ of September to $10^{\text {st }}$ of October and minimum frequencyfromNovembertoMarch (about $0 \%$ ).Cold stress $\left(<4{ }^{\circ} \mathrm{C}\right)$ can be observed from October to May with maximum frequencies ( $>90 \%$ ) in the months December, January and February. Days with strong heat stress, can be observed from $20^{\text {st }}$ of June to $10^{\text {th }}$ of September with maximum frequencies (Morethan $8 \%$ ) from 20 st of July to $10^{\text {th }}$ of August.

The relative frequencies for PET in Ardabil station is shown in Figure 5. Ardabilis consideredas oneof the coldestcities in Iran, inthis station, thermal comfort occurs from April to October, with maximum frequencies $\left(>30 \%\right.$ ) from $10^{\text {st }}$ of June to $10^{\text {th }}$ of Septemberand minimum frequency in November to April (about0 \%). Cold stress $\left(<4{ }^{\circ} \mathrm{C}\right)$ can be observed from September to June with maximum frequencies $(>95 \%)$ in the months December, January and February. Days with strong heat stressinArdabilrarelyhappens and can be observed from July to September with frequencies lessthan $2 \%$. 


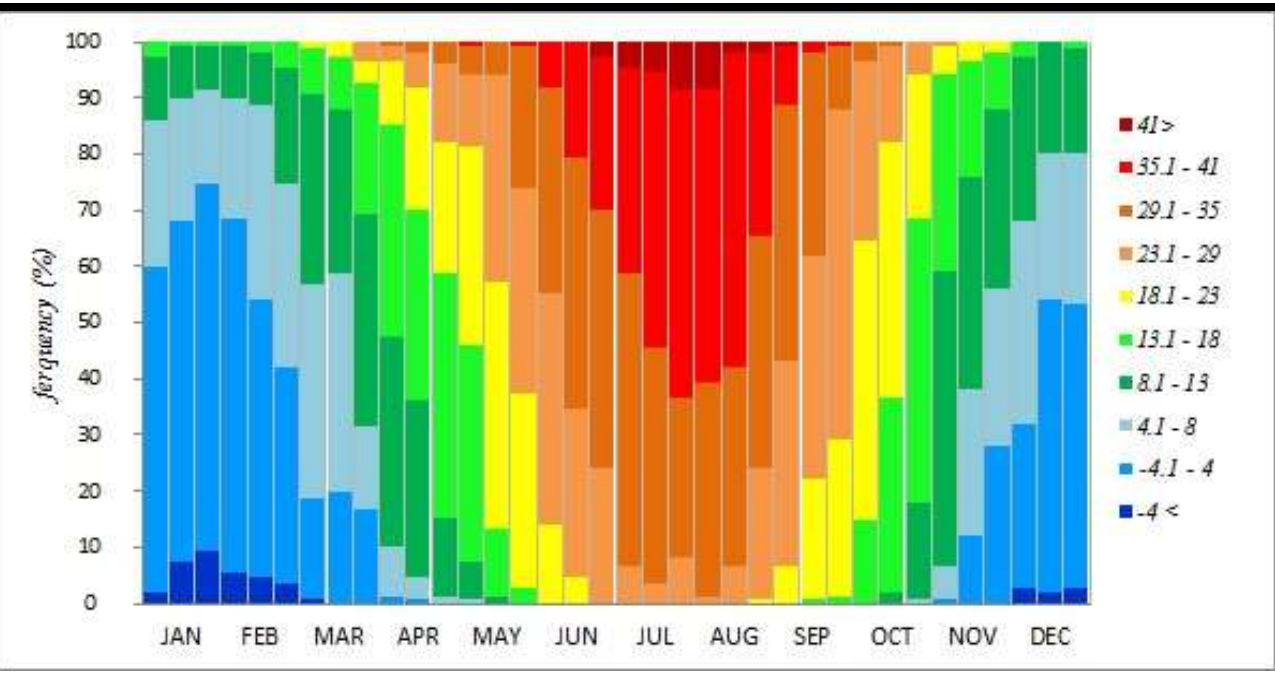

Fig.2: Probability of occurrence of different PET classes for the meteorological station Kermanshah for the period 1985-2010.

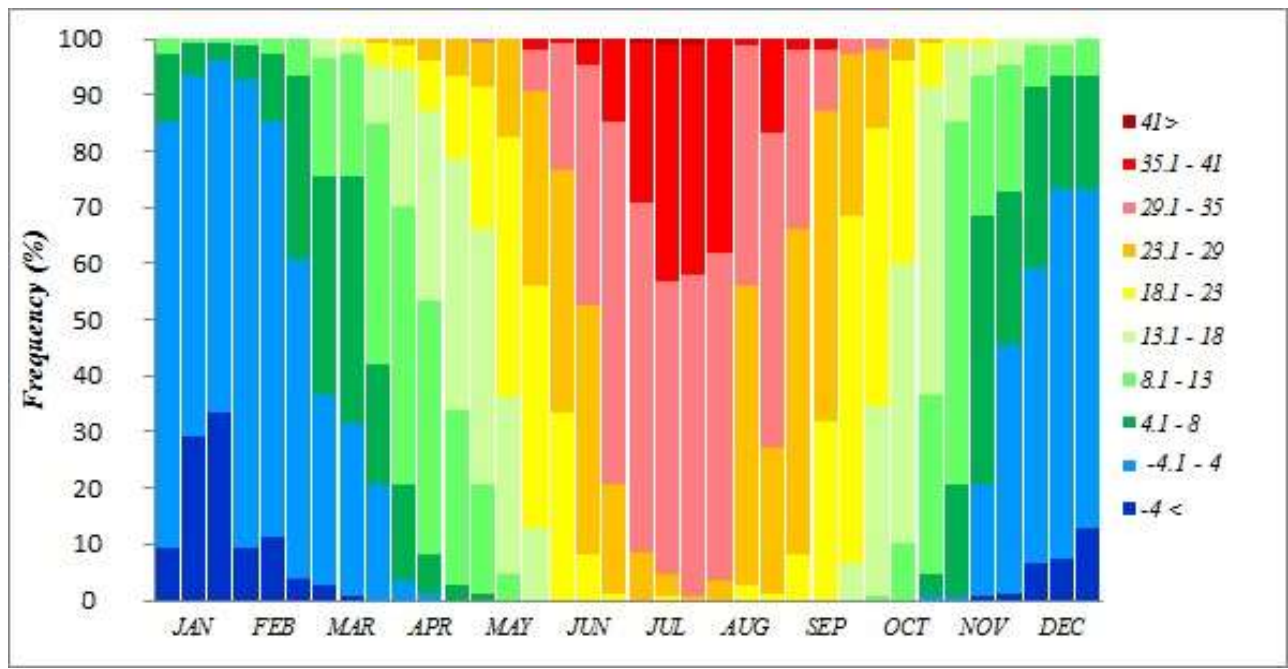

Fig.3: Probability of occurrence of different PET classes for the meteorological station Sanandaj for the period 1985-2010.

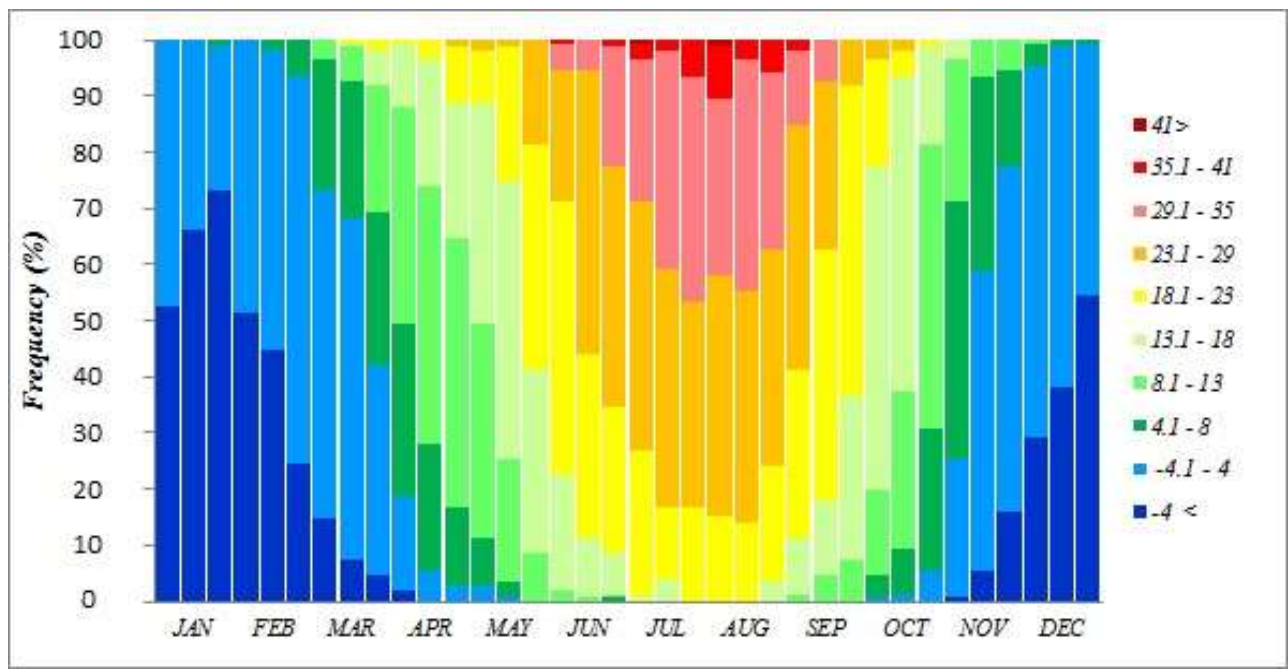

Fig.4: Probability of occurrence of different PET classes for the meteorological station Tabriz for the period 1985-2010. 


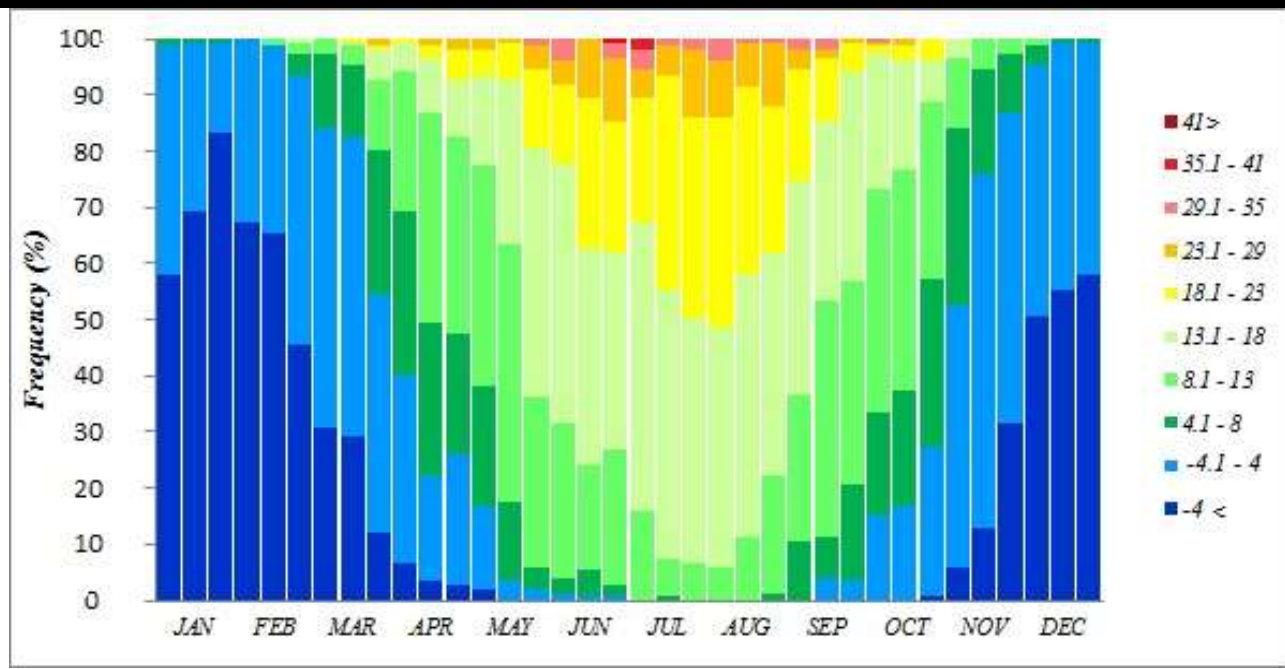

Fig.5: Probability of occurrence of different PET classes for the meteorological station Ardebil for the period 1985-2010.

Figure 6 shows the mean daily changes in the PET for Ardebil, Tabriz, Kermanshah and Sanandaj stations in the period 1985-2010. The thermal comfort zone (the numerical value of 13 to 29 degrees) is marked on the chart. In Kermanshah and Sanandaj stations, there is a cold physiological stress with different intensities from $1^{\text {st }}$ of January to $30^{\text {th }}$ of April and $20^{\text {th }}$ of October to $31^{\text {st }}$ of December. From $1^{\text {st }}$ of May to $15^{\text {th }}$ of June and $10^{\text {th }}$ of September to $20^{\text {th }}$ of October the physiological stress is zero and there is a climate comfort condition. There is a warm physiological stress with different intensities from $15^{\text {th }}$ of June to $10^{\text {th }}$ of September.

Based on PET of Tabriz station, there is a cold physiological stress with different intensities from $1^{\text {st }}$ of January to $10^{\text {th }}$ of May and $15^{\text {th }}$ of October to $31^{\text {st }}$ of December. From $10^{\text {th }}$ of May to $15^{\text {th }}$ of July and $15^{\text {th }}$ of August to $15^{\text {th }}$ of October the physiological stress is zero and there is a climate comfort condition. There is a warm physiological stress with slight intense from $15^{\text {th }}$ of July to $15^{\text {th }}$ of August.

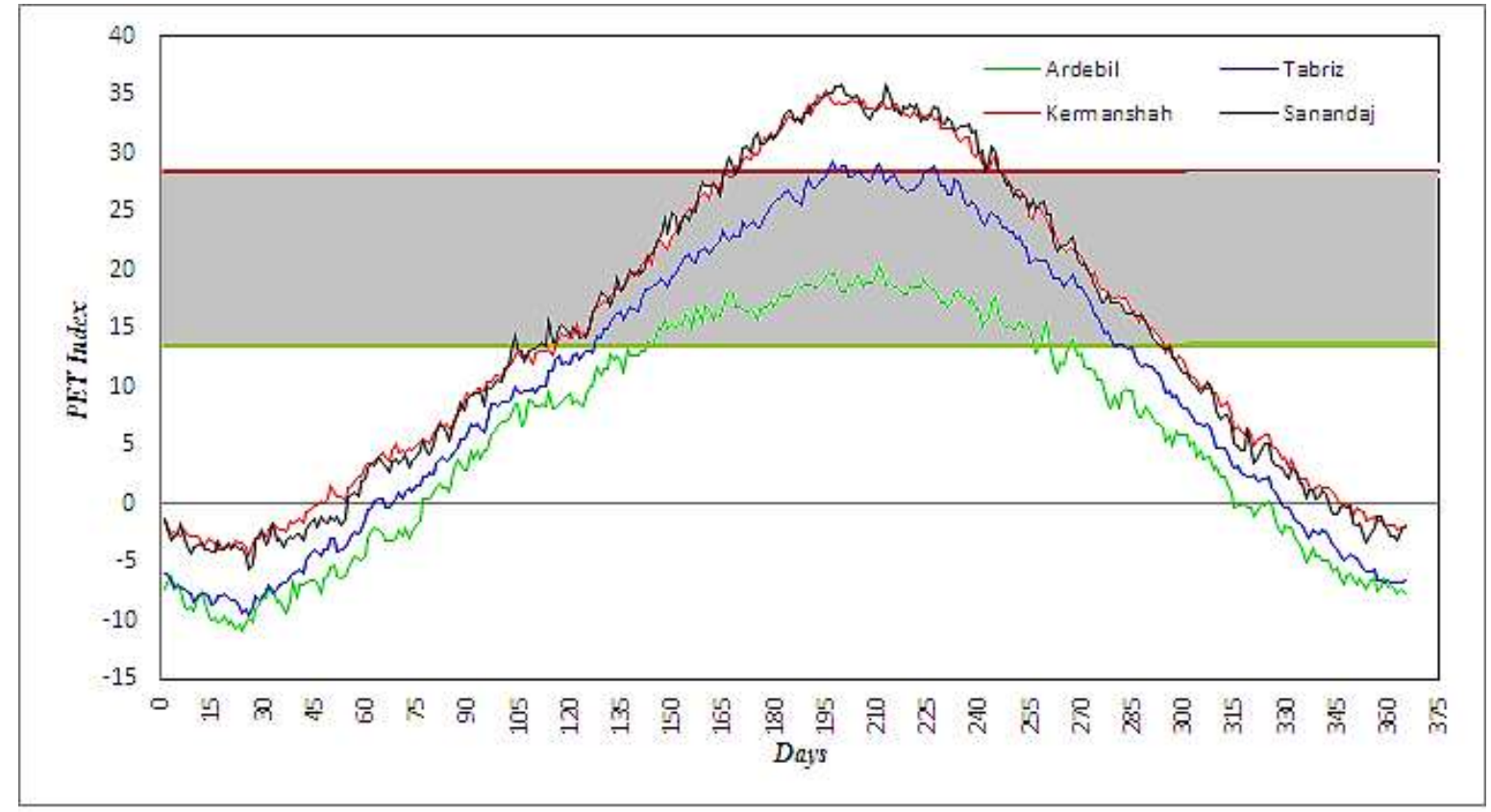

Fig.6: PET variations and comfort range at selected stations for 1985-2010

In Ardebil station, there is a cold physiological stress with different intensities from $1^{\text {st }}$ of January to $15^{\text {th }}$ of May and $20^{\text {st }}$ of September to $31^{\text {st }}$ of December. From $15^{\text {st }}$ of May to $20^{\text {th }}$ of September, the physiological stress is zero and there is a climate comfort condition. There isn't warm physiological stress in Ardebil station throughout the year. 
In order to study the temporal and spatial changes in climate comfort, the monthly maps predicted and evaluated.Figure 7 shows the PET conditions for January. In this month,there isan extreme cold stress dominates in the provinces of Azerbaijan ${ }^{1}$, Kurdistan andHamadan, whilethere is a strong cold stress in the provinces of Kermanshah.The PET condition for February isthe same asJanuary. There is an extreme cold stress in the northern parts of the study area such as Azerbaijan, Kurdistan and Hamadan, whilea moderate cold stress is dominant in west parts of Kermanshahsuch as Sarpole Zahab station (Fig. 8).In March, the amount of cold stress compared to the months of January and February have been reduced.There is an extreme and strong cold stress in the northern parts of the region such as Azerbaijan, Kurdistan and Hamadan and moderate cold stress in west parts of Kermanshah (Fig. 9).In April, the western parts ofKermanshah provincessuch as Sarpole Zahab are associated with comfortable perception, while there is a slight cold stress in Jolfa, Khoy, Parsabad, Miyaneh and Aslamabad stations and moderate to strong cold stress in other areas (Fig. 10).

In the month of May by increasing the air temperature, the Coldstressis reducedinthe study area, sothere is slight heat stress in the west parts of Kermanshah provinces andslightcold stress to comfort conditions in most parts of Azerbaijan, Kurdistan, Hamadan and Kermanshah (Fig. 11).The PET condition forJuneisindicateda strong to moderate heat stress in the western parts of Kermanshah provinces and Parsabad station, a slight heat stress in most parts of study area and climatic comfort conditions in theStationsof Ahar, Sarab, Ardebil, Khalkhal, Khodabandeh, Khorramdareh and Bijar (Fig. 12).

July is the hottest month in the study area. The PET condition forJulyisindicateda strong to moderate heat stress in the western parts of Kermanshah province, a slight tomoderate heat stress in most parts of Azerbaijan, Kurdistan, Hamadan and Kermanshah provinces and climatic comfort conditions in theStationsof Ahar, Sarab, Ardebil and Khalkhal (Fig. 13).Physiological equivalent temperature index in August is also similar to July, so that the PET condition shows a strong heat stress in the western parts of Kermanshah province such as Sarpole Zahap station, aslight to moderate heat stress in most parts of Azerbaijan, Kurdistan, Hamadan and Kermanshah provinces and climatic comfort conditions in theStationsof Sarab, Ardebil and Khalkhal(Fig. 14).In September, the intensity of the heat stress compared with the months of July and August have been reduced. There is a moderate heat stress in the western parts of Kermanshah province, slight heat stressin theStationsof Kermanshah, Aslamabad, Sanandaj, Khoy, Jolfa, Miyaneh and Parsabad, climatic comfort conditionsin most parts of region and slight cold stress in theStationsofSarab, Ardebil, Khalkhal and Khodabandeh (Fig. 15).In October,the heat stress reduced and cold stress has started in the northern parts of study area.The PET condition for October isindicatedclimatic comfort conditionsin the western parts of Kermanshah province, a slight to moderate cold stressin most parts of region and strong cold stress in theStationsofSarab, Ardebil and Khalkhal (Fig. 16).The physiological equivalent temperature condition in November shows a moderate cold stress in the western parts of Kermanshah province and strong to extreme cold stress in Otherareas (Fig. 17).In December, the severity of cold stress has increased. The PET condition in December shows a strong cold stress in the western parts of Kermanshah province and extreme cold stress in otherareas (Fig. 18).

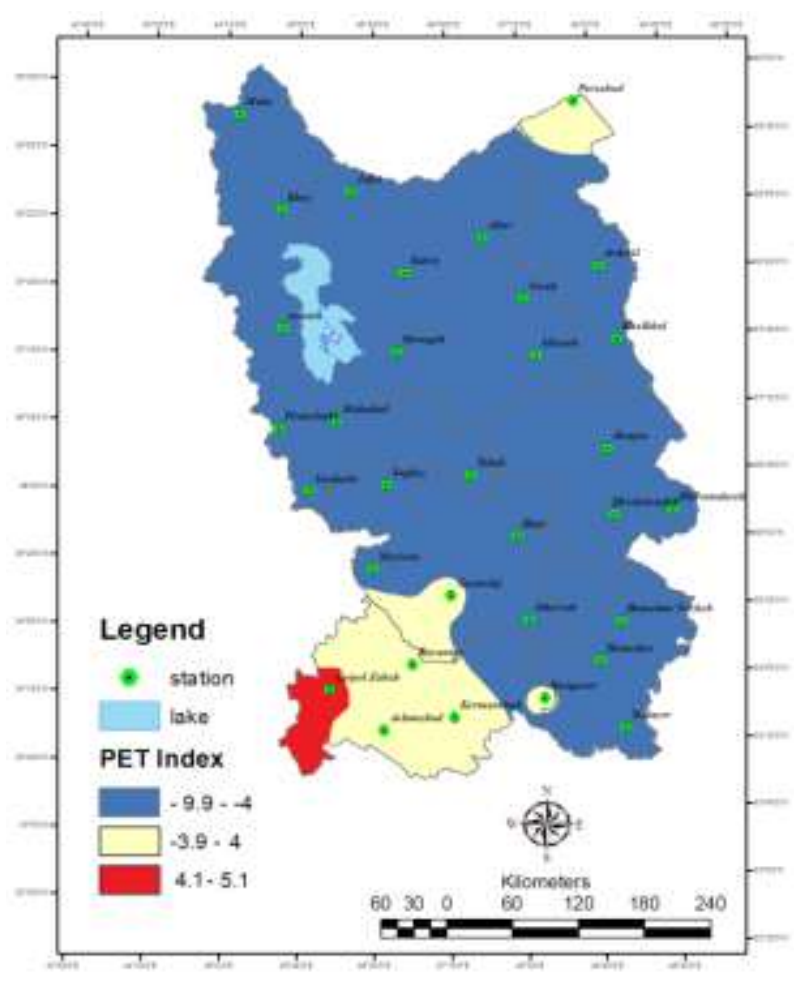

Fig.7: Geographical distribution of PET in January

${ }^{1}$. Inthispaper,Azerbaijanincludesthe provinces ofEast

Azerbaijan, West Azerbaijan, Ardabil and Zanjan 


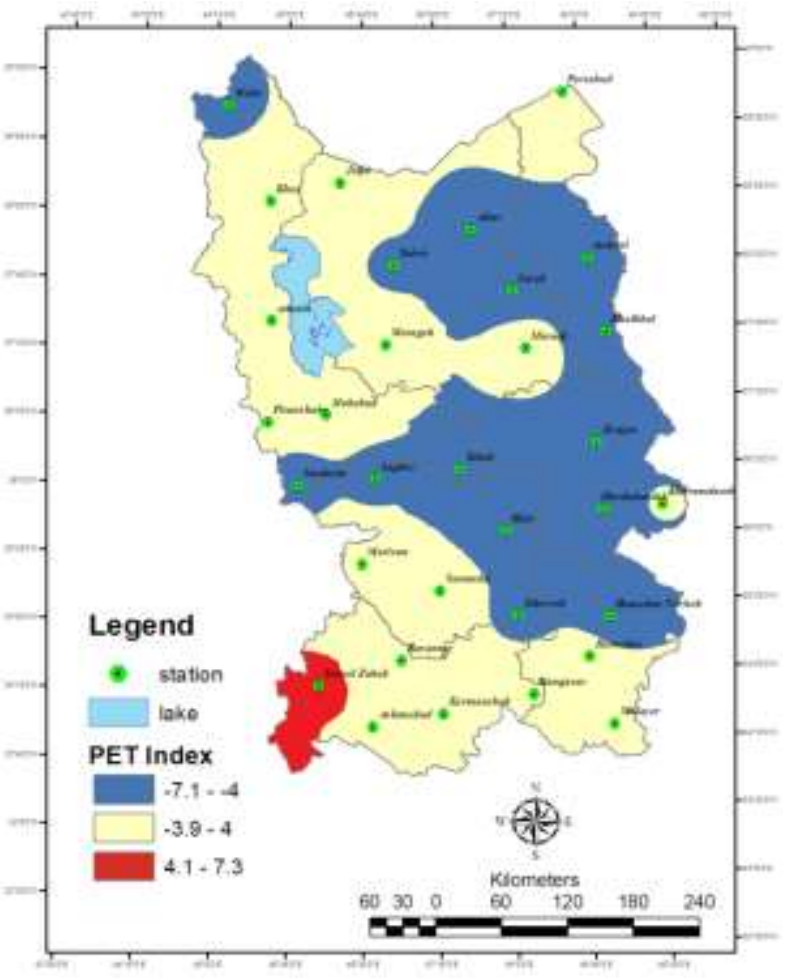

Fig.8: Geographical distribution of PET in February

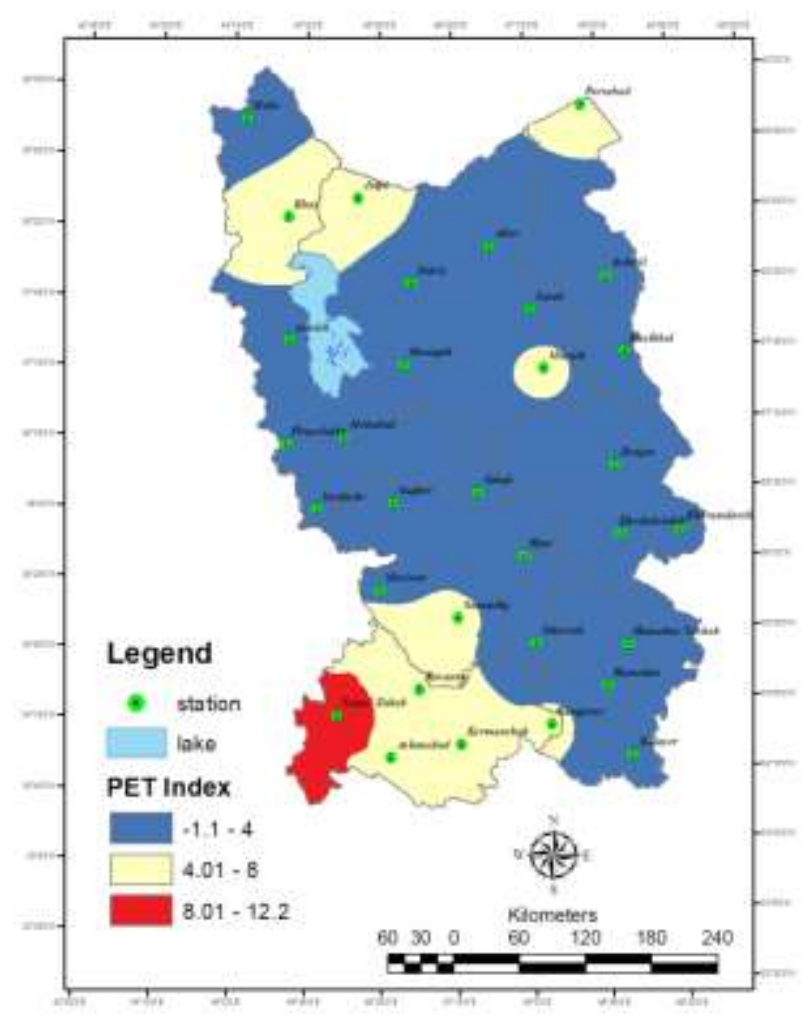

Fig.9: Geographical distribution of PET in March

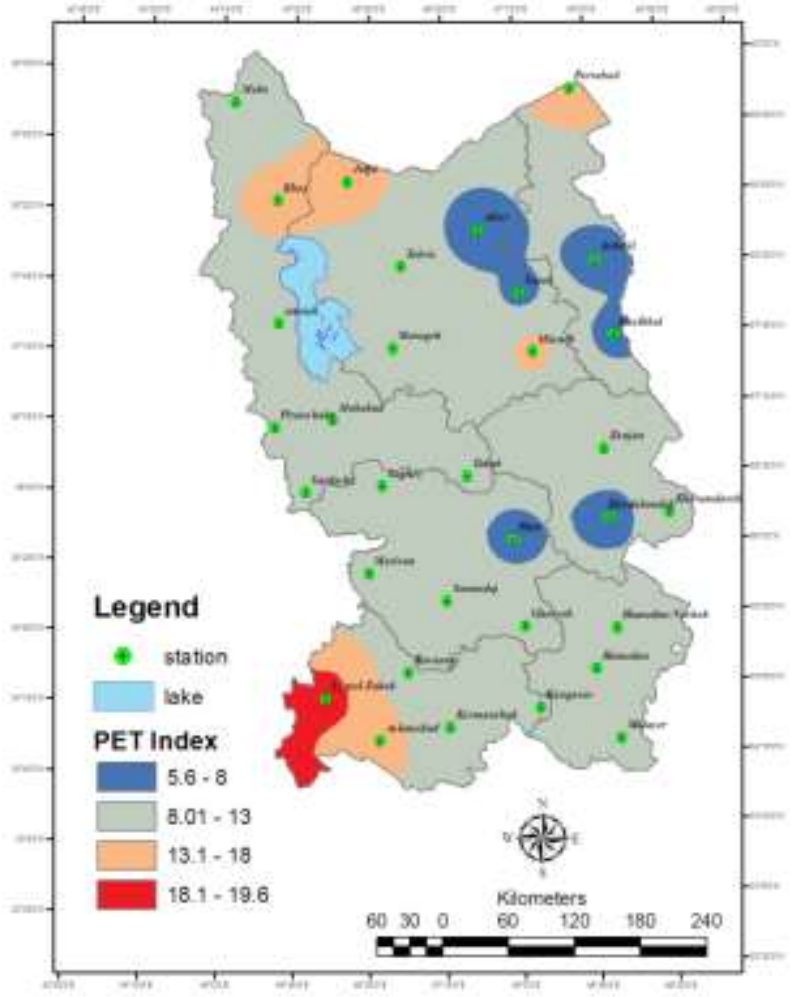

Fig.10: Geographical distribution of PET in April

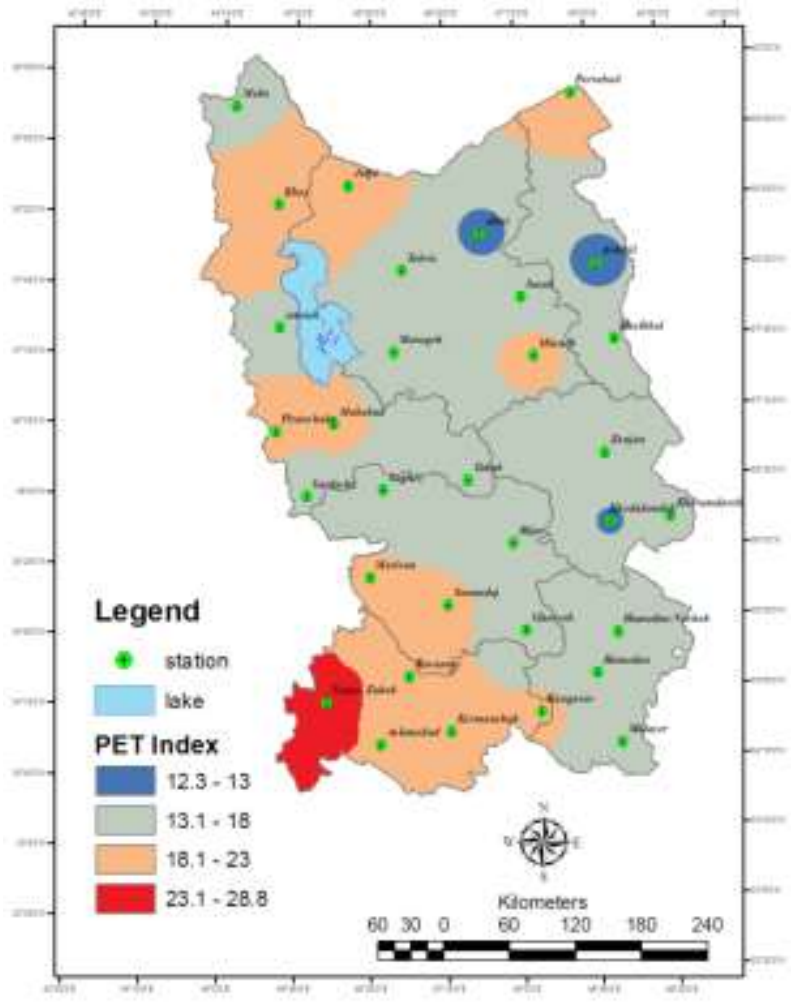

Fig.11: Geographical distribution of PET in May 


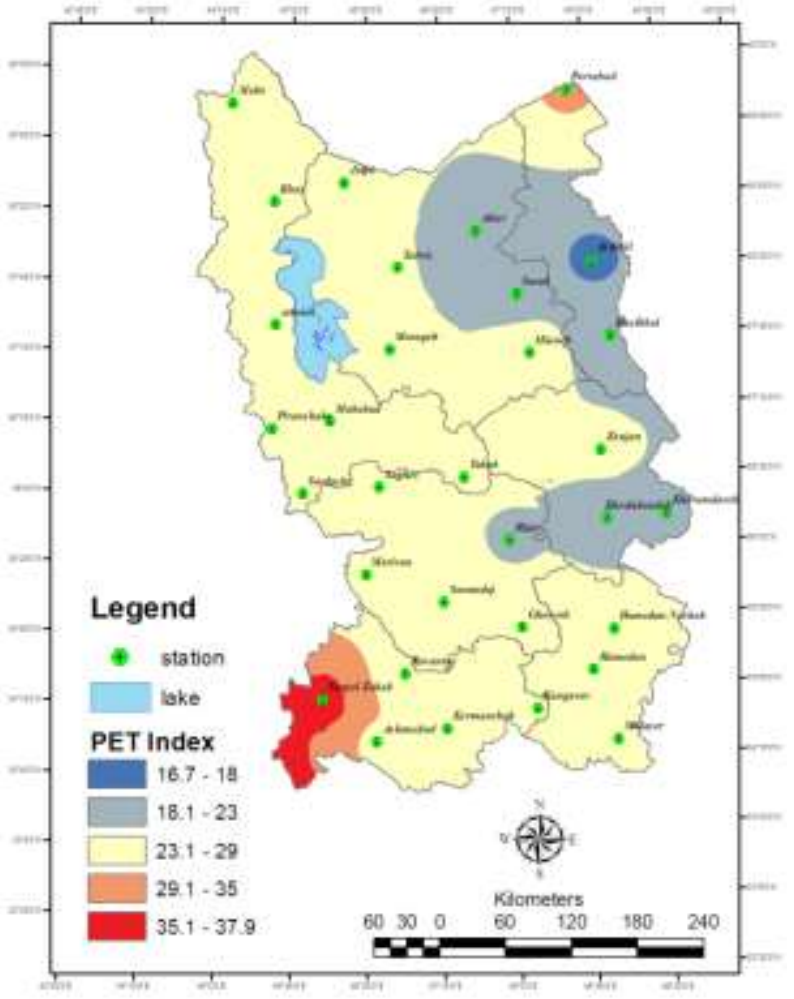

Fig.12: Geographical distribution of PET in June

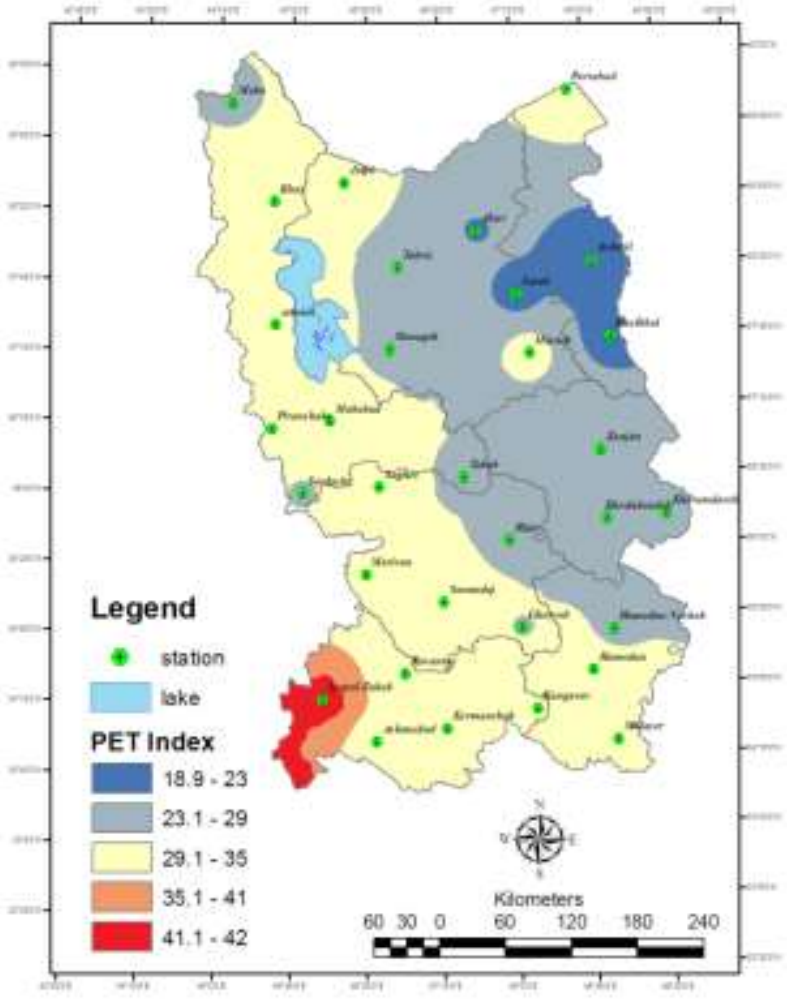

Fig.13: Geographical distribution of PET in July

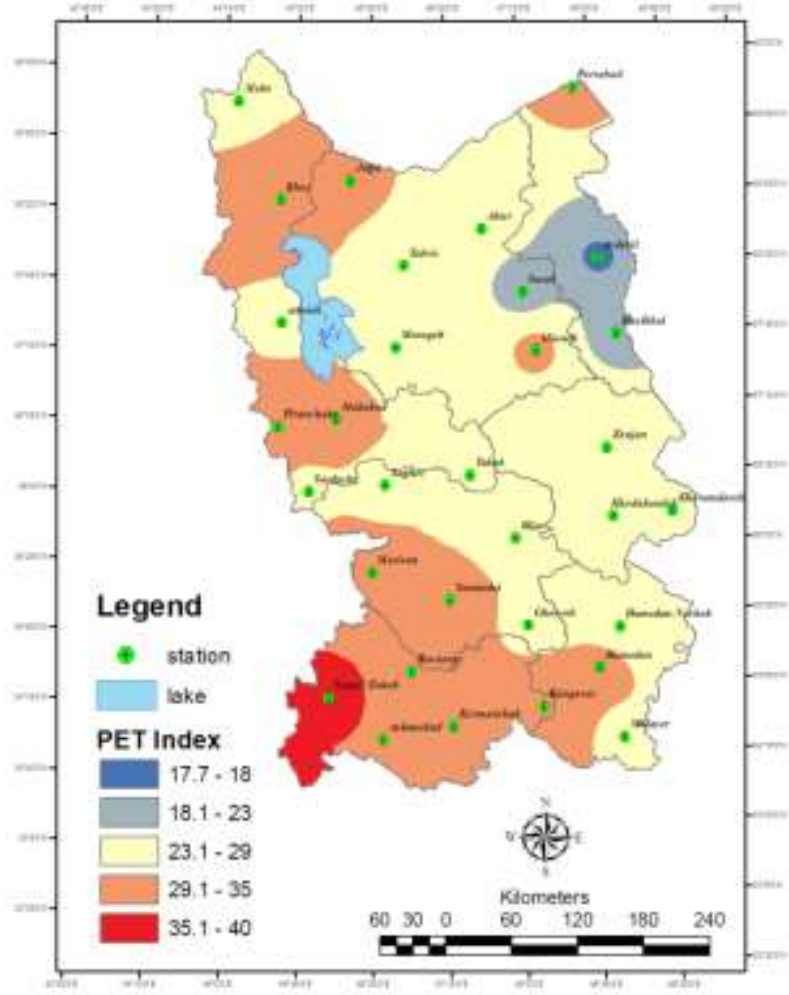

Fig.14: Geographical distribution of PET in August

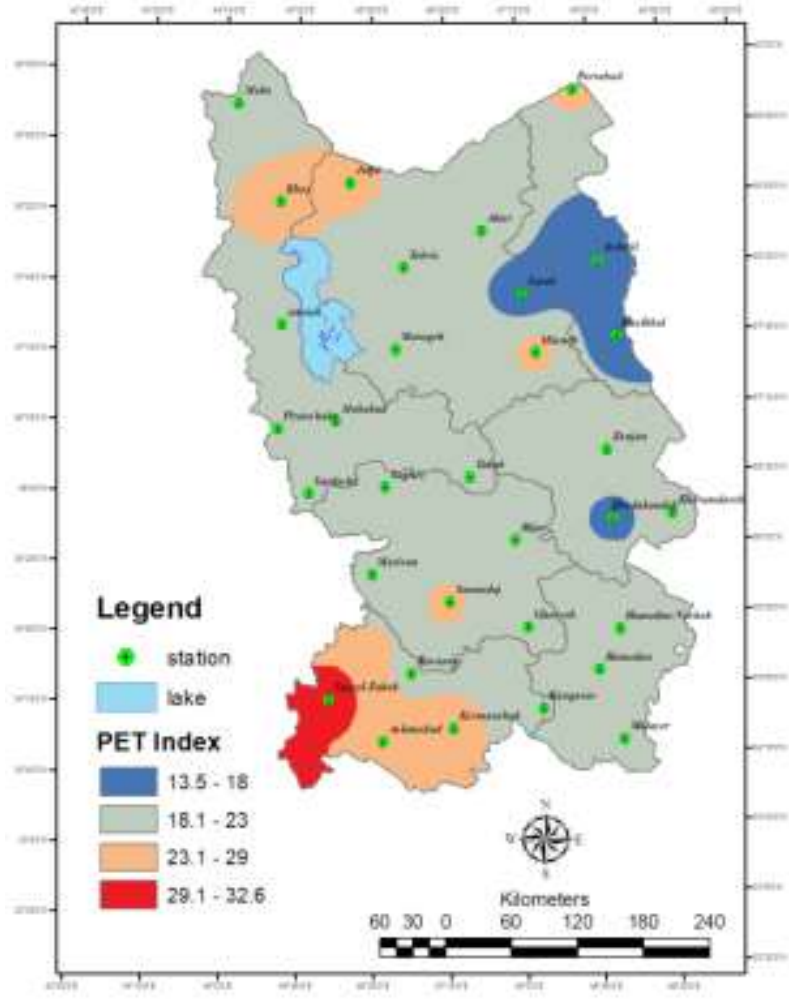

Fig.15: Geographical distribution of PET in September 


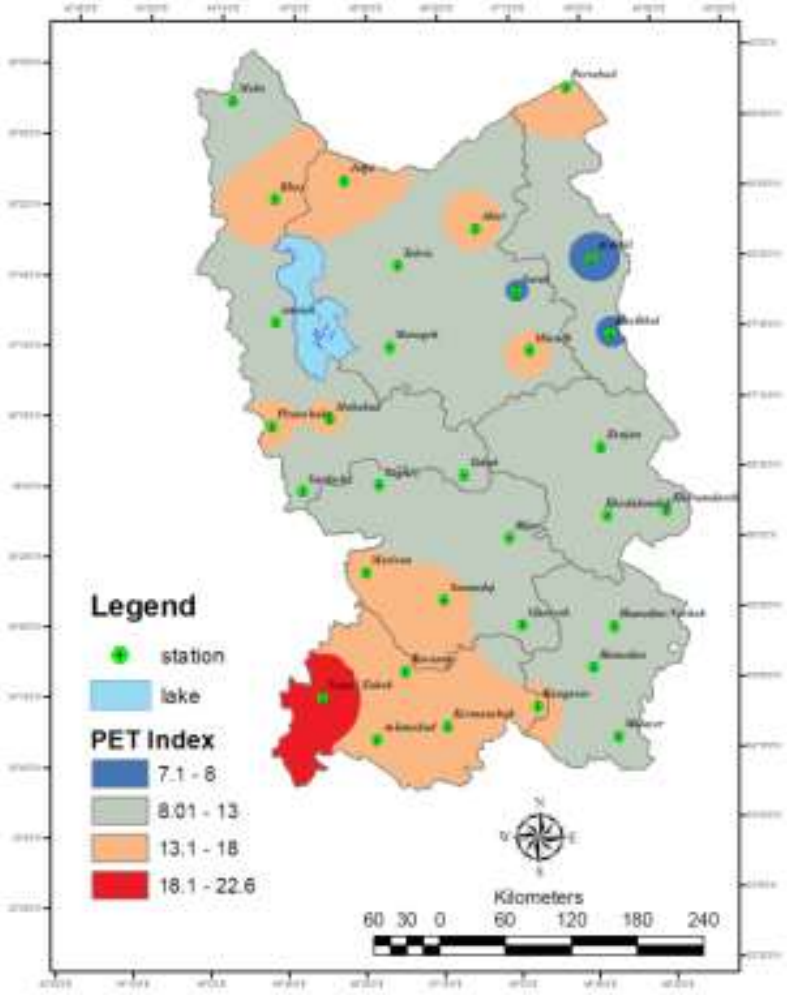

Fig.16: Geographical distribution of PET in October

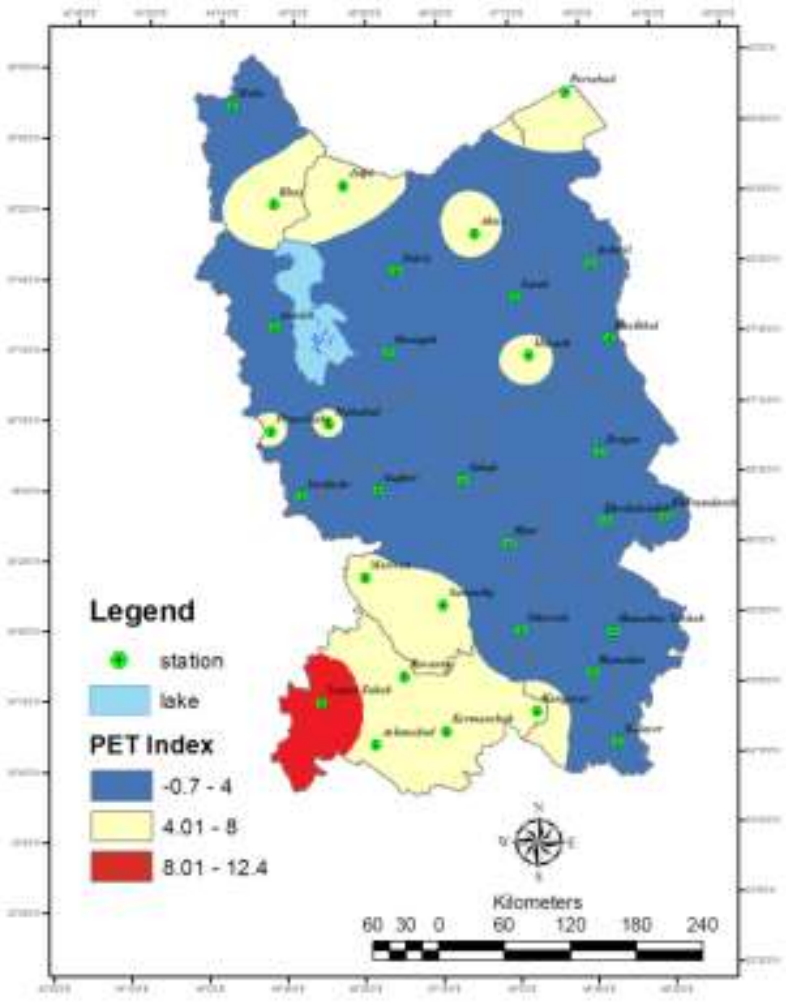

Fig.17: Geographical distribution of PET in November

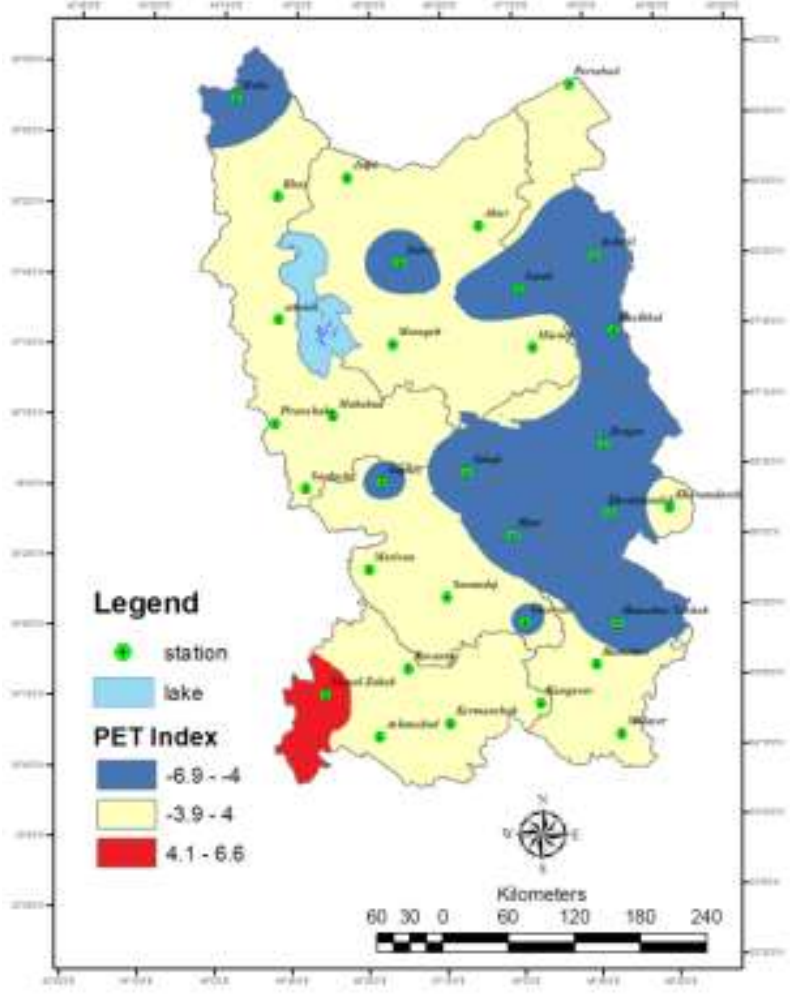

Fig.18: Geographical distribution of PET in December

\section{CONCLUSIONS}

The

extent

ofIranindifferentlatitudesandclimaticdiversity, providinggoo dconditionsfortourist activities(in terms of bioclimate and climate comfort) in all seasons.In this paper, the climatic tourism potential and thermal comfort conditions during the period (1985-2010) were analyzed forwest and north westof Iran. In the study area, the most suitableareasfortourist activitiesin the summerareAzerbaijan and especially Ardebilprovince.Inspring andautumn, the bestthermal comfort conditions in the province of Kermanshahand Kurdistan and in winterthe bestthermal comfort conditions in the western parts ofKermanshahis provided.The findings of this study can be valuable for tourism in the region.The analysis of climate and bioclimate, especially if presented in a clear and simple way to beunderstandable for everyone, provides a basis for the promotion of tourism destinations (Zaninović and Matzarakis 2007). The information can be used by tourist managers in advertising, by tourists who want to decide when to take their holidays and by physicians to warn their patients for the periods that are unsuitable for health therapy. For example, the people who have difficulty tolerating thesummer heat, such as the elderlies, should choose the best period of bio meteorological conditions to take their vacations, which prevail in the southern parts of region such as Kermanshah in March and December, in the middle sectors such as 
Kurdistanin April, May and October and in the northern parts such as Azerbaijan and Hamadan in June and September. For sportsmen who prefer an active anddynamic vacation, pleasant or even cool conditions would be more convenient than summer heat, when the body has to usesthe energy for defense from heat.

\section{REFERENCES}

[1] Ataei H, HasheminasabS. 2012. Regionalization and Evaluation of Seasonal Human Bioclimate of Semnan Province. Journal of Basic and Applied Scientific Research, vol 2(5), pp4740-4750.

[2] Ataei H, Hasheminasab S. 2013.Determination of suitable calendar for Tourism in Ahwazutilizing Physiological Equivalent Temperature (PET). Journal of Life Science. Vol 2 (7) June 2013: 104 - 109.

[3] FallahiA. 2012. Kurdistan Tourism Climate Index zoning using TCI. Proceedings of the Fourth Global Conference geography student.

[4] Esmaili R, Fallah Ghalhari G. 2014. An Assessment of Bioclimatic Conditions for Tourists - A Case Study of Mashhad, Iran. Atmospheric and Climate Sciences, 2014, 4, 137-146.

[5] Farajzadeh H, Matzarakis A. 2009. Climate Potential for Tourism in Northwest of Iran. Meteorological Applications 16, 545-555.

[6] Fanger P. O. 1972. Thermal comfort. New York: McGraw Hill.

[7] Gagge A. P, Fobelets A. P,Berglund L. G. 1986. A standard predictive index of human response of the thermal environment. ASHRAE Transactions 92, 709731.

[8] Höppe P. 1999. The physiological equivalent temperature $-a$ universal index for the biometeorological assessment of the thermal environment. Int. J. Biometeorol. 43, 71-75.

[9] Matzarakis A,Rutz F,Mayer H. 2007. Modeling Radiation flaxes in simple and complex environments - Application of the Ray man model, Int. J.Biometeoral. (51,323-334).

[10] Matzarakis A. 2007. Assessment Method for Climate and Tourism Based on Daily Data Development in Tourism Climatology. 52-58.

[11] Matzarakis A. 2009. The Seventh Internationalconference on urban climate. 29June 3July 2009 Yokhama. Japan.

[12] Matzarakis A,Mayer H. 1996. Another kind of environmental stress: Thermal stress. WHO News 18, 7-10.

[13] Matzarakis A,Mayer H. 1997. Heat stress in Greece. Int. J. Biometeorol. 41, 34-39.
[14] Matzarakis A,Mayer H, Iziomon M. G. 1999. Applications of a universal thermal index: Physiological equivalent temperature. Int. J. Biometeorol. 43, 76-84.

[15] Matzarakis A, Rutz F, Mayer H. 2000. Estimation and calculation of the mean radiant temperature within urban structures. In: Biometeorology and Urban Climatology at the Turn of the Millennium (ed. by R.J. de Dear, J.D. Kalma, T.R. Oke and A. Auliciems): Selected Papers from the Conference ICB-ICUC'99, Sydney, WCASP-50, WMO/TD No. 1026, 273-278.

[16] Matzarakis A. 2006. Weather and climate related information for tourism. Tourism and Hospitality Planning and Development 3: 99-115.

[17] Ranjbar F, MuqbilM, Arslany M. 2010. Climate with anannual reviewof the tourist city MARVDASHT. Journal of Geography. Third year. No. 7, pp. 90-79.

[18] Rutty M, Scott D. 2014. Bioclimatic comfort and the thermal perceptions and preferences of beach tourists, Int. J. Biometeorol. 58, 1-9.

[19] Spagnolo J, R. de Dear .2003. A field study of thermal comfort in outdoor and semi-outdoor environments in subtropical Sydney Australia. Building and Environment, 38: 721-738.

[20] UNWTO .2008. WordTourism Barometer. Volume6, Number2. Madrid: United Nations Word Tourism Organization Word Tourism Organization. Madrid, Spain.

[21] United Nations World Tourism Organization (UNWTO) UNWTO tourism highlights.2013. Edition.UNWTO:http://dtxtq4w60xqpw.cloudfront.net /sites/all/files/pdf/unwto_highlights13 en_lr.pdf.

Accessed 30 Sep 2013.

[22] VDI. 1998. Guideline VDI3787. Part I: Environmental meteorology. Methods for the human biometeorological evaluation of climate and air quality for the urban and regional planning at regional level. Berlin: Beuth. Düsseldorf: Verein Deutscher Ingenieure, $52 \mathrm{pp}$.

[23] World Meteorological Organization.1999. Climate and human health. World Climate News, 14, 3-5.

[24] Word Tourism Organization. 2006. Tourism 2020 Vision. WTO Publication Unit. Word Tourism Organization. Madrid. Spain.

[25]Zaninović K,Matzarakis A. 2009. The bioclimatological leaflet as a means conveying climatological information to tourists and the tourism industry, Int J Biometeorol (2009) 53:369-374. 